\title{
CURRÍCULO E FORMAÇÃO DE PROFESSORES DE INGLÊS EM DUAS UNIVERSIDADES: QUESTÕES E DESDOBRAMENTOS ${ }^{1}$
}

\author{
SCHOLAR CURRICULUM AND ENGLISH TEACHERS' EDUCATION IN TWO UNIVERSITIES: INQUIRIES AND UNFOLDMENTS
}

EL PLAN DE ESTUDIOS EN FORMACIÓN DE PROFESORES DE INGLÉS EN DOS INSTITUCIONES DE EDUCACIÓN SUPERIOR: CUESTIONAMIENTOS Y DESPLIEGUES

\author{
BROSSI, Giuliana Castroi \\ FURIO, Mariana ${ }^{3}$ \\ TONELLI, Juliana Reichert Assunção ${ }^{4}$
}

\begin{abstract}
RESUMO
Este estudo discute em que medida a educação contemporânea encontra espaço na formação inicial de professores e analisa os processos de reelaborações curriculares dos cursos de letras nas Universidades Estaduais de Londrina e de Goiás concernente à formação inicial de professores de língua inglesa para crianças e professores de português para falantes de outras línguas. Trata-se de estudo de caso com dados advindos de análise documental, questionário e entrevistas. Os resultados indicam que os temas levados para as aulas se pautam nos documentos prescritivos, no campo de atuação dos docentes e consideram, parcialmente, as necessidades locais e possiveis contextos de atuação profissional.
\end{abstract}

Palavras-chave: Formação de professores de línguas. Educação na contemporaneidade. (Re)construção de currículo.

\section{ABSTRACT}

This study discusses how contemporary education and its consequences meet into teachers initial training and analyses syllabus re-making processes at Literature school of Universidade Estatal de Londrina and Universidade Estatal de Goiás regarding Teaching English as a Second Language (TESL) initial training for children and Portuguese teachers for speakers of other languages. The results indicate that the themes taken to the classes are based on prescriptive documents, in the field of the teachers' performance and partially consider the local needs and possible contexts of professional performance. Keywords: TESL training. Contemporary education. Syllabus (re) making.

\section{RESUMEN}

Este estudio discute en qué medida la educación contemporánea encuentra espacio en la formación inicial de maestros y analiza los procesos de reelaboración curricular de la carrera de letras en las Universidades Estatales de Londrina y Goiás con respecto a la capacitación inicial de maestros de inglés para niños y maestros de portugués a hablantes de otros idiomas. Este es un caso de estudio con datos de análisis documentales como cuestionarios y entrevistas. Los resultados indican que los temas llevados a las clases se basan en documentos prescriptivos, en el campo del desempeño de los docentes y se considera parcialmente las necesidades locales y los posibles contextos de desempeño profesional.

Palabras clave: Formación de profesores de idiomas. Educación contemporánea. (Re)construcción del currículum.

\footnotetext{
${ }^{1}$ Artigo desenvolvido no âmbito do Grupo de Pesquisa FELICE (CAPES-CNPq), liderado pela terceira coautora e no Projeto de Pesquisa "Avaliação da Aprendizagem em Línguas Estrangeiras nas Séries Iniciais de Escolarização (AALESE)", cadastrado na Pró-reitoria de Pesquisa e Pós-graduação da Universidade Estadual de Londrina, sob número 11779, coordenado também pela terceira coautora. Número de aprovação do Comitê de Ética em Pesquisa Envolvendo Seres Humanos (CEP -UEL): 07609319.4.0000.5231

2 Universidade Estadual de Goiás - UEG - Goiás - Brasil.

${ }^{3}$ Universidade Estadual de Londrina - UEL - Paraná - Brasil.

${ }^{4}$ Universidade Estadual de Londrina - UEL - Paraná - Brasil.
} 


\section{INTRODUÇÃO}

Como formadoras de professores atuamos em contextos diferentes, mas temos em comum alguns questionamentos relacionados à formação inicial de professores de inglês (doravante LI). Acreditamos ser importante transitar por algumas especificidades de contextos quando refletimos acerca do currículo dos cursos de licenciatura em letras 5 : o mundo onde vivemos e trabalhamos como professores, o perfil dos nossos futuros professores e os objetivos destes cursos. Neste artigo direcionamos nosso olhar para o futuro, buscando responder às seguintes perguntas. A Universidade Estadual de Londrina e a Universidade Estadual de Goiás disponibilizam, em seu currículo, oportunidades para os professores de inglês em formação inicial se prepararem para atuar na educação contemporânea? e; ii) Em que medida os currículos dos cursos investigados alinham-se às demandas dos contextos específicos de ensino de LIC e PFOL?, duas áreas em crescente expansão.

Tais questionamentos nos levaram a refletir sobre perspectivas já presentes na realidade profissional de professores licenciados em letras. Comungamos da percepção de Gimeno-Sacristán (2013a, p. 9) ao ponderar que "o currículo também nos serve para imaginar o futuro, uma vez que ele reflete o que pretendemos que os alunos aprendam e nos mostra aquilo que desejamos para ele e de que maneira acreditamos que possa melhorar." Por isto, defendemos a necessidade de problematizar o currículo que tem sido construído nas salas de aula dos cursos de letras, uma vez que, ao final de sua formação inicial, o professor é considerado apto a entrar para o mercado de trabalho.

Pautadas nas oportunidades de atuação deste profissional nos contextos analisados, além do desenvolvimento de habilidades e de saberes necessários para lidarem com a diversidade e com a pluralidade linguístico-cultural, consideramos essencial problematizar as escolhas curriculares transpostas para a sala de aula nos cursos de formação de professores de inglês e suas possíveis relações com o contexto onde eles poderão atuar.

Com vistas a oportunizar diálogos com outras Instituições de Ensino Superiores (IES) brasileiras, neste artigo objetivamos a) discutir em que medida a educação contemporânea e seus desdobramentos encontram espaço na formação inicial de professores de inglês na UEL e na UEG; b) analisar os processos de reelaborações curriculares dos cursos de licenciatura em letras da Universidade Estadual de Londrina (UEL) e da Universidade Estadual de Goiás (UEG) ${ }^{6}$, no que tange à formação inicial de professores de língua inglesa para crianças (LIC), professores de português para falantes de outras línguas (PFOL) e professores aptos a lidar com a superdiversidade característica do século XXI. Para isso, propomos uma reflexão em um estudo colaborativo entre professores formadores de ambas as instituições, UEG e UEL.

\section{DELINEANDO O CENÁRIO DE ATUAÇÃO DO PROFESSOR DE LÍNGUAS DO SÉCULO XXI}

\footnotetext{
5 O uso dos termos "Letras" e "curso(s) de Letras" são utilizados para os cursos de graduação que formam professores de inglês.

${ }^{6}$ As duas universidades onde as autoras atuam como docentes.
} 
O panorama atual, com discursos de globalização, extinção de fronteiras de tempo e espaço para o convívio com a multiculturalidade e a relevância da sensibilização a respeito ao Outro, demanda reelaborações curriculares nos cursos de letras, atendendo, em parte, às tendências das políticas de internacionalização do ensino superior, das revisões epistemológicas acerca dos conhecimentos sobre ensino e aprendizagem, dentre outras.

Estudos têm discutido a complexidade da conjuntura mundial em relação à educação linguística, e no que concerne à formação de professores aptos a atuarem nesse contexto intrincado que se apresenta, de superdiversidade ${ }^{7}$ (VERTOVEC, 2007). De acordo com Finardi e Archanjo, (2018, p. 174), a globalização e seus efeitos reforçam a "centralidade da linguagem, a mobilidade das pessoas e a diversidade criando um cenário complexo de superdiversidade" (VERTOVEC, 2007, p. 1025). O autor conclama os cientistas sociais e formuladores de políticas a levar em conta a conjunção de etnicidade com alcance de outras variáveis ao considerar a natureza das várias 'comunidades', sua composição, trajetórias, interações e necessidades de serviços públicos.

Se há um discurso de movimento global, que incentiva programas de internacionalização, a mobilidade com oferta de participação em programas de pós-graduação no exterior, o currículo, com temas e discussões que contribuam com a melhor atuação e adaptação do profissional graduado em letras, sofre também, por consequência, ressignificações.

No entanto, conforme Pimenta e Lima (2012, p. 33), alguns cursos de formação não estão conectados com a realidade onde o futuro professor irá atuar.

[...] os currículos de formação têm-se constituído em um aglomerado de disciplinas isoladas entre si, sem qualquer explicitação de seus nexos com a realidade que thes deu origem. Assim, nem sequer se pode denominá-las teorias, pois são apenas saberes disciplinares em cursos de formação, que em geral estão completamente desvinculados do campo de atuação profissional dos futuros formandos. (PIMENTA; LIMA, 2012, p. 33).

Por uma perspectiva foucaultiana, Egido (2020) ratifica uma lacuna já apontada em pesquisas anteriores (SANTOS, 2009; TONELLI; CRISTOVÃO, 2010). No que tange à formação de professores de línguas estrangeiras para crianças (LEC), considera que

[...] a inclusão de disciplinas, sejam elas optativas ou obrigatórias, bem como constituição de campos de estágios docentes obrigatórios não dizem respeito simplesmente a uma inclusão, mas a uma luta discursiva, ou seja, de poder pela consideração de LEC como conhecimento profissional igualmente válido. (EGIDO, 2020).

\footnotetext{
${ }^{7}$ Segundo Vertovec (2007), o conceito de superdiversidade relaciona-se às novas conjunções e interações de variáveis que se apresentam nos países que recebem imigrantes de diversas etnias e nacionalidades nos padrões de imigração presentes nas últimas décadas no Reino Unido.
} 
Comungamos da percepção do autor de que há uma luta discursiva ${ }^{8}$ entre campos de saberes considerados - e que se consideram mais viscerais que os demais sem, no entanto, preparar professores para atuar nos cenários emergentes (TONELLI, 2016; 2017) de ensino de LIC. $O$ que pode ser também aplicado ao ensino de PFOL, bem como para agir no contexto de diversificada fluidez do século XXI. Afinal,

Se entendemos a língua como uma prática social de construção de sentidos, ao ensinarmos língua estamos ensinando formas de entender/construir o mundo - e a contribuição social disso fica evidente. As pessoas, quando aprendem língua e se percebem construindo sentidos para/do/no mundo no processo de aprendizagem, podem desenvolver uma atitude mais respeitosa diante dos sentidos das outras pessoas, as identificações e desidentificações, suas e de outras. (JORDÃO, 2013, p. 78, grifo do autor).

A formação de professores que defendemos articula-se com um profissional consciente de que as aulas de línguas, sejam elas, de LIC, de PFOL ou para o trabalho com a (super)diversidade que vivenciamos, constroem sentidos e "ensinam formas de entender/construir o mundo", formando cidadãos "para/do/no mundo" (JORDÃO, 2013, p. 78). É com esse olhar que refletimos acerca do currículo dos referidos cursos de letras.

O conceito de currículo é demasiado complexo para ser descrito de maneira unânime e, muito menos, "aplicável" de forma generalizada a todos os contextos (GIMENO-SACRISTÁN, 2013a, 2013b; PACHECO, 2003, 2005) e, por isto, buscamos discutir o currículo dos cursos de letras a partir de leituras que nos permitam dialogar com o cenário onde o professor de línguas estará inserido após o término de sua licenciatura. Para Gimeno-Sacristán (2013a, p. 9), o currículo "é um componente formador da realidade do sistema de educação no qual vivemos" e que, portanto, "dá forma à educação".

A perspectiva das teorias críticas pós-estruturalistas de currículo nos possibilitam não somente delinear, mas questionar os processos de (re)elaboração curriculares. Desta forma, o currículo não se encerra em uma única área ou linha de pesquisa, mas encontra-se entrelaçado a um aglomerado de "outros territórios da educação inclusive externos a ela" e é por essa razão que o currículo pode ser considerado uma "metateoria" (GIMENO-SACRISTÁN, 2013a, p. 10). A esse respeito, Pacheco (2005, p. 39) aponta que "nesse aspecto, devemos reconhecer que a fragmentação do campo curricular compreender-se-á, preferencialmente, pela inexistência de um consenso não sobre o que significa, mas do que deve veicular e o modo como deve ser organizado".

Para o autor, buscar uma definição não se faz tão urgente quanto questionar sobre quem define e de que forma é definido o percurso de aprendizagem em determinado contexto (PACHECO, 2005). Da mesma forma, para Gimeno-Sacristán (2013b, p. 34) estar "em consonância com uma visão menos idealista da educação, mais próxima da realidade e comprometida com ela," significa

\footnotetext{
${ }^{8}$ Emprestamos o termo "luta discursiva" de Egido (2020) para salientarmos os diálogos que são possibilitados ao tratar dos temas de formação docente nas esferas de LIC, PFOL e da superdiversidade. Segundo o autor, "ao compreender que "todo conhecimento torna possível o exercício do poder" (FOUCAULT, 2015, p. 225), essas práticas de formação são autorizadas pelo status institucional", com o qual alguns professores formadores lidam, numa luta discursiva em que cada professor busca validação para seu regime de verdade.
} 
dizer que "discutir ou pesquisar currículo supõe tocar algo visível e expresso socialmente." O autor nos leva a considerar que, ao analisar o currículo devemos nos propor um distanciamento das burocracias e das formas materiais ("planos de estudos" ou "programas escolares") que comumente são compreendidas por currículo.

Portanto, adotamos tais concepções acerca do currículo para analisar os dados mencionados, pois, em concordância com Pacheco (2003), optamos pela utilização de um referencial com base em investigação empírica: contrapondo às teorizações sobre o tema e compreendendo a questão curricular "na base de uma política que envolve diversidade e conflitos." (PACHECO, 2003, p. 116). Encontramos um possível diálogo entre os estudos curriculares e o papel da formação de professores no e para o século XXI - ou seja, onde estão presentes o discurso da globalização, as mediações tecnológicas, e que nos permitem perceber de forma mais expressiva a diversidade dentro dos cenários das instituições públicas de formação de professores.

Defendemos que no contexto atual, diante da comprovada crescente oferta de LIC no Brasil (TANACA, 2017), a formação de professores para atuar nesse campo parece ser uma questão que começa a ser considerada pelos cursos de letras (TONELLI; CRISTOVÃO, 2010). Por muito tempo discutiu-se quem deve ser o profissional responsável pelo ensino de LE nos anos iniciais (SANTOS, 2009; TONELLI; FERREIRA, BELO-CORDEIRO, 2017; PADRE, 2019). Embora a discussão pareça não estar encerrada, pautamo-nos na resolução CNE/CEB 7/2010 (BRASIL, 2010), que estabelece, em seu artigo 15, que língua estrangeira moderna é um componente curricular obrigatório a partir do sexto ano do EF. Em seu artigo 31, parágrafo primeiro, a resolução deixa claro que “§ $1^{\circ}$ Nas escolas que optarem por incluir Língua Estrangeira nos anos iniciais do Ensino Fundamental, o professor deverá ter licenciatura específica no componente curricular". (BRASIL, 2010, grifo nosso).

Assim, entendemos que cabe ao profissional de letras a tarefa de ensinar inglês nos anos iniciais e, por isto, defendemos um currículo de formação inicial para o ensino de LIC que contemple a inserção de disciplinas, estágio nos anos iniciais da educação básica, iniciação científica e/ou ações de extensão que favoreçam o desenvolvimento de capacidades e competências para lidar com as especificidades da atividade docente de LIC. Acreditamos que uma das demandas da sociedade atual seja "o ensino significativo de língua(s), por meio de um trabalho mais localizado" como afirmam Silvestre, Brossi e Borelli (2017, p. 49), amparadas por Jordão e Fogaça (2007) e o desenvolvimento da percepção crítica (MONTE MÓR, 2013). Deste modo, para contemplar um ensino de LIC com ênfase na construção de sentidos por lentes mais localizadas, em busca do desenvolvimento da percepção crítica nas crianças, o ensino de LIC deve ser contemplado na formação inicial, ou seja, fazer parte do currículo do curso de letras.

Outro campo que nos interessa e está em expansão (FURTOSO, 2015) é o ensino de português para falantes de outras línguas (PFOL). Advogamos, outrossim, que ao refletir acerca de currículo no curso de letras, a inserção deste tópico é condição sine qua non para o debate.

Para Furtoso (2015), a concepção e a implementação do exame para certificação em língua portuguesa para estrangeiros (Celpe-Bras) foram fatores determinantes para a consolidação e expansão da área. Atualmente, juntam-se a esse fator 
[...] o incremento dos intercâmbios do Brasil com outros países, o aumento do ingresso de estudantes estrangeiros nos programas acadêmicos das universidades brasileiras, a presença crescente do Brasil no exterior por meio dos leitorados, as implicações político-pedagógicas do Celpe-Bras, bem como as ações da Comunidade dos Países de Língua Portuguesa (CPLP). (FURTOSO, 2015, p. 156).

Mendes (2016) destaca o caráter pluricêntrico ${ }^{9}$ da LPE, seu ensino e formação de professores para esse fim, tecendo reflexões direcionadas à forma de planejamento de ações para o ensino e a formação destes profissionais.

Schoffen e Martins (2016), por sua vez, apresentam as perspectivas portuguesa e brasileira para o ensino de português como língua adicional (PLA), apontando os contrastes existentes entre elas. Os autores destacam que o aumento de ações voltadas para a internacionalização do ensino superior e o favorecimento da posição econômica do Brasil resultaram na procura por cursos de língua portuguesa. Além disso, ao considerar a crescente onda imigratória, ao criar novas demandas das crianças, filhos dos imigrantes, nas escolas brasileiras, encontramos justificativa para promover a reflexão acerca da formação de professores para esse público (SCHOFFEN; MARTINS, 2016).

\section{APROXIMANDO AS NOVAS DEMANDAS DE FORMAÇÃO AO CONTEXTO ANALISADO}

Esta investigação é um estudo de caso (YIN, 2005) e insere-se no campo das pesquisas qualitativa e interpretativista. Para analisar os processos de reelaborações curriculares consideramos três conjuntos de dados: o Projeto Pedagógico de Curso (PPC) dos dois cursos; as respostas obtidas a partir de um questionário eletrônico; e entrevistas a duas professoras.

Para a análise documental, levamos em conta os PPC do curso de letras inglês/português da UEG e do curso de letras inglês da UEL. O segundo conjunto de dados constitui-se das respostas fornecidas a partir do questionário online utilizando o GoogleForms, o qual foi criado para identificar, na perspectiva dos respondentes e organizado em dois blocos: I) o grau de relevância dos professores formadores acerca dos tópicos abordados e; II) a frequência com que abordam tais tópicos em suas aulas na graduação, utilizando uma escala Likert de 1 a 5 , sendo 1 nada relevante e 5 extremamente relevante.

Na UEG, o questionário eletrônico foi enviado a 26 professores, dos quais obtivemos 13 respostas. Na UEL o mesmo questionário foi enviado para dez professores do curso de letras inglês e obtivemos quatro respostas. Neste artigo, consideramos as respostas obtidas nos seguintes tópicos do formulário eletrônico: 1) LIC e; 2) PFOL.

As entrevistas ( $3^{\circ}$ conjunto de dados) foram realizadas com duas professoras que se disponibilizaram a aprofundar-se nas questões concernentes aos currículos e que atuam em cargos de gestão das unidades que as abrigam ${ }^{10}$, nas quais atuam também como docentes. $C$ é graduada em letras português/inglês, mestre em Letras e Linguística Aplicada e doutora em Políticas

${ }^{9}$ A autora define o caráter pluricêntrico da língua portuguesa por esta apresentar mais de um centro de referência, de onde emanam variadas normas (MENDES, 2016, p. 294).

${ }^{10}$ Por questões éticas, os nomes das entrevistadas são preservados e as identificamos por meio das letras C (no caso da UEG) e L (no caso da UEL). 
Públicas, Estratégias e Desenvolvimento e atua no referido curso a 17 anos. A professora L é graduada em letras anglo-portuguesa, mestre em Educação e doutora em Estudos da Linguagem, atuando no referido curso desde 2009. Optamos por utilizar a entrevista como um dos instrumentos de geração de dados, pois encontramos nela um meio de gerar informações diretamente pelos sujeitos de pesquisa (SILVA et al., 2006).

Amparadas na análise documental, realizada a partir dos PPC dos dois cursos ${ }^{11}$, passamos a considerar os objetivos dos cursos, os perfis dos licenciandos e outras questões concernentes à configuração atual dos cursos, incluindo semiotizações das entrevistadas ( $\mathrm{C}$ e L) acerca dos déficits identificados no currículo.

Conforme o PPC do curso, na UEL, o objetivo é "formar professores para atuar nas áreas de língua inglesa e literaturas da língua inglesa, no ensino fundamental e médio, capazes de aliar a formação teórica com a prática profissional, de forma crítica e reflexiva" (UNIVERSIDADE ESTADUAL DE LONDRINA, 2018, p. 10).

Por sua vez, o objetivo geral do curso da UEG câmpus Inhumas, de acordo com o PPC, é "desenvolver a capacidade intelectiva, formando profissionais interculturalmente competentes, capazes de lidar de forma crítica com as linguagens nos contextos oral e escrito, conscientes de sua inserção na sociedade e das relações com o outro". (UNIVERSIDADE ESTADUAL DE GOIÁS, 2018, p. 27).

Nota-se que, em ambos os cursos, se busca a formação de um profissional reflexivo capaz de agir na sociedade - educação básica - a partir da prática consciente.

Recuperando o PPC da UEL, evidencia-se a preocupação com a adequação do currículo à realidade da comunidade, uma vez que em $2013^{12}$ uma comissão - do Departamento de Letras Estrangeiras Modernas ${ }^{13}$ - realizou encontros com o propósito de estudar a reestruturação dos cursos de letras inglês, letras espanhol e letras francês ${ }^{14}$. Foram definidos os princípios norteadores para um novo PPC, com base no perfil dos licenciados dos cursos pelos desafios contemporâneos e os possiveis campos de atuação profissional.

Assim, esta matriz, delineada como "o básico" na fala de L, possui 3.200 horas organizadas em três núcleos: de estudos de formação geral; de aprofundamento e diversificação de estudos na área de atuação profissional; e de estudos integradores para o enriquecimento curricular. Os núcleos são perpassados por quatro eixos: técnico-científico, acadêmico crítico, pedagógico (oficinas de iniciação à docência) e integrador ${ }^{15}$.

A entrevistada $L$, atuante como coordenadora do curso de letras/inglês na UEL, delineia como "o básico" as 3.200 horas organizadas no PPC da UEL em três núcleos: de estudos de formação geral; de aprofundamento e diversificação de estudos na área de atuação profissional; e

\footnotetext{
${ }^{11}$ Salientamos que os PPC analisados são aqueles em vigor no momento da escrita deste artigo.

${ }^{12}$ Instrução de Serviço $n^{\circ}$ 12/2013 de 30 de abril de 2013.

${ }^{13}$ O Departamento é formado por três cursos: letras inglês, letras espanhol e letras francês.

${ }^{14}$ As sugestões emergiram da necessidade de mudanças observadas pelo corpo docente e a partir de um questionário aplicado, em 2013, aos alunos do 4o. ano de letras inglês e letras espanhol, que objetivavam conhecer a opinião dos discentes sobre os cursos.

${ }^{15} \mathrm{O}$ eixo integrador busca contemplar a prática como componente curricular e consiste das atividades do Núcleo de Estudos Integradores para o Enriquecimento Curricular: Atividade Acadêmica Complementar e o Estágio Curricular Obrigatório.
} 
de estudos integradores para o enriquecimento curricular. Os núcleos são perpassados por quatro eixos: técnico-científico, acadêmico crítico, pedagógico (oficinas de iniciação à docência) e integrador.

Por sua vez, o comentário de C, docente da UEG, ao comentar o PPC alerta para uma possivel limitação das mudanças durante a reelaboração, pois posteriormente serão contrapostas em seu comentário sobre a "formação do indivíduo".

Encontramos, nas palavras de C e de L, ecos das acepções de Pacheco (2005) acerca de um projeto que contempla a continuidade de ações, elaborado pela comunidade educativa que, ao responderem à pergunta 3 (Como você avalia as alterações curriculares efetivadas desde que você cursou a graduação e atualmente?) afirmam, conforme Excerto 1, que as adequações foram acertadas, pois foram feitas justamente para atender novas demandas na formação profissional dos professores de inglês.

\section{Excerto 1}

Algumas alterações foram pertinentes, pois visaram adequar o currículo às necessidades ou mudanças na área da educação básica e formação profissional (ex: libras, estágio). (C )

Eu acho que o curso avançou significativamente no aprimoramento linguístico [...]. Ficava um déficit muito grande no aprimoramento linguístico. As próprias disciplinas, né? Teve muitas mudanças, o modo de ensinar, o modo de conceber ensino e aprendizagem. (L)

L cita, no Excerto 1, que as alterações são evidentes no ensino da língua inglesa ("aprimoramento linguístico"). Esta leitura pode evidenciar o que veremos na análise dos gráficos de relevância e frequência dos tópicos sobre diversidade: há, de fato, uma lacuna entre o currículo que se propõe formador para a realidade do século XXI, mas que na prática permanece aquém da superdiversidade, individual e coletiva, presente nos contextos.

Continuamos as discussões acerca da reformulação do currículo nas duas IES a partir das falas das duas entrevistadas. A professora $\mathrm{C}$, em respostas aos dois primeiros questionamentos feitos (Qual foi a última alteração curricular substancial do curso de letras nesta instituição?; e Como essa/s alteração/ões foram feitas? A quem coube a decisão?) atesta que as alterações no curso da UEG foram realizadas em 2015, "colegiadas e decididas pelo conselho superior da universidade". Sobre o curso da UEL, L faz menção ao início da reelaboração curricular a qual ocorreu em 2013.

\section{Excerto 2:}

O nosso curso $\cdots$ iniciou a [...] reformulação, começou muito antes dessa obrigatoriedade, dessa reformulação. Às vezes, a gente faz reformulação em função de uma obrigatoriedade, por força de lei, e outras vezes, por você sentir a necessidade mesmo. Então, a decisão acho que veio embasada em avaliações que o colegiado fez de diagnósticos para entender o que podia apontar, onde podia melhorar, quais eram as lacunas. (L) 
As falas das professoras evidenciam que o corpo docente dos dois cursos investigados está à frente nos processos de reelaboração curricular ao ressaltar que o início das reelaborações foi anterior à obrigatoriedade e partem do contexto local. Tal movimento nos remete a Pacheco (2003) para quem construir currículo demanda uma postura política do professor posto que a ele compete propor e deliberar, em espaços coletivos onde as decisões são tomadas. Assim, ao reelaborar o currículo, entendemos que os cursos investigados desconstroem, de certo modo, a ideia de que pensar, propor e implementar currículo são atos hierárquicos, centralizados e burocráticos (PACHECO, 2003).

No caso da UEL, L ao descrever as ações "embasada em avaliações que o colegiado fez", entendemos que a reelaboração é consonante com Pacheco (2005) sobre um projeto provindo da comunidade educativa, na continuidade de ações e decisões marcadas por interesses dos envolvidos na comunidade escolar. Além disto, torna-se compreensível como construção social, por ser parte do processo ininterrupto que envolvem interesses pessoais, demandas da sociedade fluída e superdiversa, e permitir aos docentes atuantes nos cursos contemplar os tópicos incorporados na reelaboração.

As informações das participantes encontram respaldo na análise realizada a partir dos PPC dos dois cursos. Por ocasião da publicação da resolução n. 2 de $1^{\circ}$ de julho de 2015, a qual define as diretrizes para a formação inicial e dá outras orientações para as licenciaturas, as discussões no curso de letras inglês da UEL estavam consideravelmente avançadas e as adequações que se seguiram constituem ajustes pontuais no âmbito do referido documento. Na UEG, a situação não ocorreu de forma diferente: o curso teve sua matriz curricular reformulada em 2015, o que pressupõe que as discussões se iniciaram anterior à obrigatoriedade legal.

Apesar da aparente disposição nas falas de C e L na reformulação curricular, nos dados obtidos a partir do questionário eletrônico, problematizamos se o mesmo ocorre no corpo docente. Dos 17 respondentes que participaram por meio do questionário identificamos que nos dois contextos: sete atuam com o estágio supervisionado de LI; e cinco atuam com a LI de forma específica (como gêneros textuais, língua inglesa para sala de aula etc.); juntos ministram dez diferentes disciplinas ${ }^{16}$ em seus respectivos cursos de graduação. Equiparando os dados das disciplinas que ministram às áreas de interesses de pesquisa dos respondentes, obtivemos 26 tópicos. Essa análise preliminar indica que as áreas de interesse de pesquisa dos professores participantes estão diretamente relacionadas às disciplinas que ministram, possibilitando para estes o exercício do poder (FOUCAULT, 2015), nas práticas de formação já "autorizadas pelo status institucional" (EGIDO, 2020) mantidas nas disciplinas autorizadas institucionalmente. Portanto, ainda que considerem determinadas áreas importantes e merecedoras de atenção na formação inicial, percebe-se que os docentes podem não se sentir suficientemente confortáveis para abordar temáticas como LIC e PFOL, ou decidam perpetuar essa luta discursiva.

Ao responderem à quarta pergunta do roteiro de entrevista (Sabemos que há tópicos/temas que não são contemplados no decorrer dos quatro anos de formação inicial de professores de

\footnotetext{
${ }^{16}$ Além das disciplinas já mencionadas os docentes ministram também: Oficina de Iniciação à Docência: Ensino de Inglês na Educação Básica, Linguística Aplicada, Latim, Gêneros textuais, Escrita acadêmica e Políticas linguísticas.
} 
línguas. O que você considera essencial e ainda não tem sido tratado adequadamente na graduação?), as entrevistadas assim se posicionam:

\title{
Excerto 3:
}

\begin{abstract}
Os cursos de licenciatura ainda focam muito no ensino da sua especificidade e não a formação do indivíduo, isto é, forma-se professores para uma disciplina que não a compreende como um conjunto de saberes necessários para a formação do indivíduo. (C)

[...] a questão das tecnologias no ensino. Por mais que a gente tente tratar em algumas ementas $[\cdots]$ está muito aquém do potencial ... tanto dominar ferramentas .... ter estrutura na Universidade $[\cdots]$ porque o presente e o futuro está muito ligado a essa tecnologia e as mudanças na sociedade são mais rápidas do que na educação $\cdots$ até incorporar essas questões novas leva um pouco de tempo. (L)
\end{abstract}

A professora C refere-se aos cursos de licenciatura em geral para apontar que os professores não são preparados para a formação do indivíduo, e sim para o ensino das disciplinas específicas de cada curso. Seu discurso está em concordância com Pimenta e Lima (2012, p. 33) acerca da constituição dos currículos de formação como um "aglomerado de disciplinas isoladas". Dito de outro modo, os cursos ainda se preocupam em trazer para a sala de aula vivências e experiências das disciplinas específicas, deixando de lado o caráter de formação humana do trabalho do professor. Já, no conceber de L, o lugar das tecnologias precisa ser, ainda, efetivamente incorporado, no âmbito educacional. Para ela, faltam ajustes institucionais - em termos de estrutura física - e profissionais para que os recursos tecnológicos sejam conhecidos e aplicados na formação inicial de professores de inglês.

A partir da reelaboração curricular é possivel apontar, ao menos duas disciplinas, inseridas no segundo e no terceiro ano do curso de letras da UEL que parecem atender à demanda a qual discutimos nesse artigo. A primeira intitulada "Oficina de Iniciação à Docência: Tendências Contemporâneas no Ensino de Inglês", que traz na ementa termos como 'diferentes contextos', 'inglês como língua de inclusão-exclusão', 'a diversidade da língua inglesa', 'diversidade étnicoracial, de gênero, social e linguística', que nos remete ao contexto de superdiversidade apontado por Vertovec (2007). A segunda disciplina "Estágio Curricular Obrigatório em Educação Infantil, Ensino Fundamental ou Equivalente" propõe na sua ementa o estágio curricular na esfera da educação infantil e dos anos iniciais do ensino fundamental, atendendo a uma demanda do mercado de trabalho, aproximando, assim, o professor em formação inicial do campo de atuação de LIC, um dos focos deste artigo.

Ao serem questionadas sobre como o curso de letras tem se adequado ao cenário de superdiversidade propelido pela globalização e mobilidade internacional, C assevera - Excerto 4 - a restrita presença do tema no currículo do curso onde atua; e L, por sua vez, aponta três aspectos que considera relevantes e foram levados em consideração no processo de reelaboração

\section{Excerto 4}

Não há políticas neste sentido para o curso de Letras. Há tentativas isoladas de atender à demanda de maneira superficial e restrita aos grandes centros. (C) 
[...] um dos aspectos foi a tentativa de inserção de disciplinas oriundas de diferentes áreas do conhecimento, [...] houve a inserção de disciplinas da psicologia, do serviço social, da educação, filosofia, sociologia, português, aqui, Letras; então de certa forma você traz olhares, diferentes pontos de vista, de diferentes áreas do conhecimento que ajuda, acho que construir, esse olhar mais holístico e contemplar mais a diversidade, dos temas. Eu acho que o fato da gente contemplar também [...] novas possibilidades, de campo de atuação do futuro profissional [...] por exemplo o português para falantes de outras línguas, ensino de inglês para crianças, então esses aspectos foram também, de alguma forma,[...] mas de alguma foram incorporados, [...] essa diversidade aí de campos, de possibilidade de atuação do futuro profissional. Talvez a concepção de língua que se trabalhe no curso, inglês como língua franca ajuda também a trabalhar com a diversidade; e as próprias temáticas, né, como diversidade, diversidades étnico-raciais e outros, preconceito, né, respeito, são questões que norteiam as disciplinas, discussões de textos. Então ajuda também a formar um cidadão, que leve em consideração, que esteja consciente desta superdiversidade. (L)

No Excerto 4, L ressalta a inclusão de disciplinas de diferentes áreas; que a reelaboração se manteve atenta aos contextos de LIC e PFOL; e que o trabalho em sala de aula contempla temas que se relacionam com a diversidade. A partir da fala de L, retomamos Gimeno-Sacristán (2013b, p. 23) ao nos recordar "Uma vez que admitimos que o currículo é uma construção onde se encontram diferentes respostas a opções possiveis onde é preciso decidir entre as possibilidades que nos são apresentadas, esse currículo real é uma possibilidade entre outras alternativas". Tal concepção se relaciona com as respostas obtidas no formulário eletrônico, pois a análise dos Gráficos 1 e 2 revela que a relevância dos temas (Gráfico 1), 15 professores atribuíram notas entre 4 e 5 na escala, evidenciando grande relevância ao tópico ensino de LIC. No entanto quando indicam a frequência, Gráfico 2, com que o tópico é abordado em suas aulas, apenas um apontou 5 , e nove responderam 1 e 2, mostrando que o ensino de LIC não tem sido discutido de forma frequente em suas aulas, tanto na UEG quanto na UEL. No que tange à formação de PFOL, a percepção de importância, no Gráfico 1, varia de 2 a 5 sendo que, para 13 professores, a frequência com que o tópico é abordado em suas aulas (Gráfico 2) fica entre 1 a 2. Isto é, a formação de professores para atuar no ensino de PFOL divide opiniões e a maioria dos formadores não propõe essas discussões para suas próprias disciplinas.

Gráfico 1: Relevância do ensino de LIC e PFOL (respectivamente)

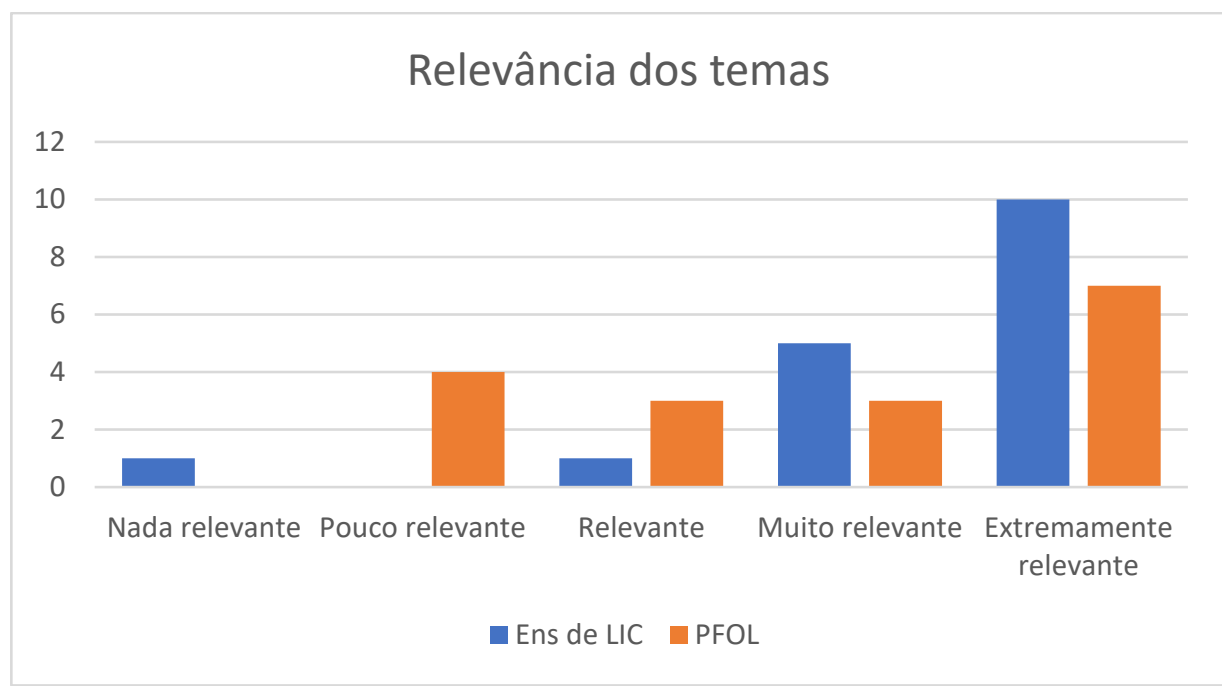

Fonte: Bloco 1 do questionário eletrônico. 
Gráfico 2: Frequência nas aulas do ensino de LIC e PFOL (respectivamente)

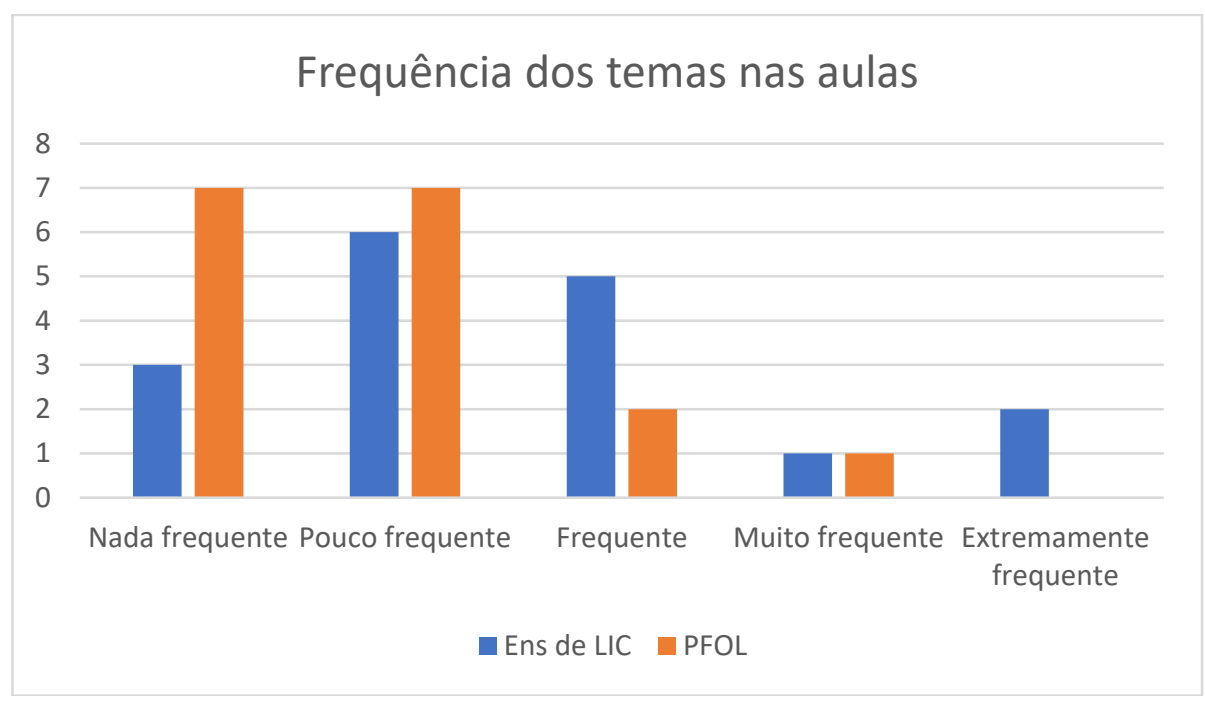

Fonte: Bloco 2 do questionário eletrônico.

Os dados nos gráficos revelam que, dos 17 professores participantes desta investigação, 15 e 10 consideram a formação para atuar no ensino de LIC e de PFOL relevante, respectivamente, tais campos do conhecimento não são frequentemente presentes nas discussões em sala de aula.

Cada professor se detém naquilo que já tem estabelecido nas disciplinas nas quais atuam na licenciatura - de um total de dez disciplinas que os 17 professores participantes ministram, 80\% são ensino de LI (em diferentes níveis) ou estágio de LI (incluído prática de ensino) - em consonância com a maior parte de seus interesses em pesquisa, cujo maior foco é a formação docente crítica e educação linguística crítica, e pelo ensino de LI (ambos com 6 menções). Ou seja, cada professor mantém o seu próprio território onde já adquiriu "o conhecimento, o poder e a identidade" (PACHECO, 2005, p. 95) que a disciplina the institui, sendo que de acordo com os dados do questionário, 12 dos 17 docentes atuam em suas respectivas IES a mais de dez anos, evidenciando grande experiência em sua área de atuação. Acreditamos que anterior à reelaboração curricular seria necessário que o currículo fosse tratado como "um componente formador da realidade do sistema de educação no qual vivemos" e que portanto "dá forma à educação" (GIMENO-SACRISTÁN, 2013a, p. 9), o que possivelmente levaria os professores formadores a se "distanciar" da visão de currículo como "saberes disciplinares em cursos de formação, que em geral estão completamente desvinculados do campo de atuação profissional dos futuros formandos" (PIMENTA; LIMA, 2012, p. 33).

\section{CONSIDERAÇÕES FINAIS}

Com vistas a problematizar como professores formadores, que atuam nas duas IES investigadas, têm lidado com a pluralidade linguística e cultural de novos campos de atuação de professores de inglês, analisamos documentos orientadores dos currículos dos cursos de letras de 
duas universidades estaduais e semiotizações dos professores formadores participantes a partir das respostas obtidas por meio de um formulário eletrônico e de entrevistas.

Os dados analisados revelam dissonância entre a visão sobre a relevância e a frequência dessas áreas na formação e mostram que formadores participantes tendem a se deter naquilo que já tem estabelecido nas disciplinas em que atuam, mantendo o seu próprio território. Nesse sentido, defendemos a democratização do currículo, compreendendo-o como uma construção social, sob as lentes da interdisciplinaridade que deveria permear as relações entre as decisões acerca do que será discutido em sala de aula. A democratização do currículo possibilitaria aos professores formadores dialogar e construir um currículo que atenda às demandas da profissão docente no cenário apresentado no decorrer desta investigação.

Defendemos que transformações no campo do currículo refletem escolhas que são coconstruídas ao longo da atuação docente em uma educação que se propõe contemporânea e que dialoga com contextos de ensino inovadores que emergem na atualidade. A configuração do curso de licenciatura em pauta apoia-se na abertura e sensibilidade dos professores formadores que efetivam o currículo em sala de aula todos os dias. Nesse sentido, entendemos que seja pertinente que os mesmos conheçam o campo de atuação atual de professores que se graduam em letras, tendo como objetivos da formação muni-los para atuar com a pluralidade linguística e cultural que discutimos.

Acreditamos que há inúmeros desafios a serem transpostos no que se refere ao currículo dos cursos de letras. No entanto, os dados revelam movimentos que consideramos como políticas contemporâneas de educação, incluindo a democratização do currículo, que é o que procuramos evidenciadar nos documentos e nas falas analisadas.

\section{REFERÊNCIAS}

1. BRASIL. Ministério da Educação. Conselho Nacional de Educação. Câmara de Educação Básica. Resolução $\mathbf{n}^{0}$ 7, de 14 de dezembro de 2010. Fixa Diretrizes Curriculares Nacionais para o Ensino Fundamental de 9 (nove) anos. Brasília: Ministério da Educação, 2010. Disponível em: http://portal.mec.gov.br/dmdocuments/rceb007_10.pdf. Acesso em: 26 set. 2019.

2. EGIDO, Alex Alves. Práticas de formação de professores de línguas estrangeiras para crianças no Brasil: um estudo discursivo foucaultiano. In: FREITAS, Carla Conti de; ROSA-SILVA, Valéria; BROSSI, Giuliana Castro (org.). Políticas e formação de professores de línguas: o que é ser professor/a hoje? Anápolis: Ed. UEG, 2020, p. 61-86.

3. FINARDI, Kyria; ARCHANJO, Renata. Washback effects of the science without borders, english without borders and language without borders programs in brazilian language policies and rights. In: SIINER, Maarja; HULT, Francis M.; KUPISCH, Tanja (ed.). Language policy and language acquisition planning. New York: Springer, 2018. p. 173-185. (Language Policy, v. 15). 
4. FOUCAULT, Michael. The punitive society: lectures at the Collège de France, 1972-1973. New York: Palgrave Macmillan, 2015.

5. FURTOSO, Viviane Aparecida Bagio. Onde estamos? Para onde vamos?: a pesquisa em português para falantes de outras línguas nas universidades brasileiras. In: LUCAS, Patrícia de Oliveira; RODRIGUES, Rosana Ferrareto Lourenço (org.). Temas e rumos nas pesquisas em linguística (aplicada): questões empíricas, éticas e práticas. Campinas: Pontes Editores, 2015. v. 1, p. 153-196.

6. GIMENO-SACRISTÁN, José. Introdução: a função da aberta da obra e seu conteúdo. In: GIMENO-SACRISTÁN, José (org.). Saberes e incertezas sobre o currículo. Porto Alegre: Penso, 2013a. p. 9-14.

7. GIMENO-SACRISTÁN, José. O que significa currículo? In: GIMENO-SACRISTÁN, José (org.). Saberes e incertezas sobre o currículo. Porto Alegre: Penso, 2013b. p. 16-35.

8. JORDÃO, Clarissa Menezes. Letramento crítico: complexidade e relativismo em discurso. In: CALVO, Luciana Cabrini Simões; EL KADRI, Michele Salles; ORTENZI, Denise Ismênia Bossa Grassano; SILVA, Kleber Aparecido da (org.). Reflexões sobre ensino de línguas e formação de professores no Brasil: uma homenagem à professora Telma Gimenez. Campinas: Pontes Editores, 2013. p. 349-369.

9. JORDÃO, Clarissa Menezes; FOGAÇA, Francisco Carlos. Ensino de inglês, letramento crítico e cidadania: um triângulo amoroso bem-sucedido. Línguas e Letras, Cascavel, v. 8, n. 14, p. 79105, 2007.

10. MENDES, Edleise. Pluricentrismo linguístico, ensino e produção de materiais de Português LE no PPPLE. In: ALVAREZ, Maria Luisa Ortiz; GONÇALVES, Luis. 0 mundo do português e o português no mundo afora: especificidades, implicações e ações. Campinas: Pontes Editores, 2016. p. 293-310.

11. MONTE-MÓR, Walkyria. Crítica e letramentos críticos: reflexões preliminares. In: ROCHA, Cláudia Hilsdorf; MACIEL, Ruberval Franco (org.). Língua estrangeira e formação cidadã: por entre discursos e práticas. Campinas: Pontes Editores, 2013. p. 31-51.

12. PACHECO, José Augusto. Políticas curriculares: referenciais para análise. Porto Alegre: Artmed, 2003. 144 p.

13. PACHECO, José Luiz. Escritos curriculares. São Paulo: Cortez Editora, 2005. 
14. PADRE, Brenda Treco. A formação pré e em serviço do professor de inglês do ensino fundamental I. 2019. 173 f. Dissertação (Mestrado em Linguística Aplicada e Estudos da Linguagem) - Pontifícia Universidade Católica de São Paulo, São Paulo, 2019.

15. PIMENTA, Selma Garrido; LIMA, Maria Socorro Lucena. Estágio e docência. São Paulo: Cortez Editora, 2012.

16. SANTOS, Leandra Inês Seganfredo. Língua inglesa em anos iniciais do ensino fundamental: fazer pedagógico e formação docente. 2009. 274 f. Tese (Doutorado em Estudos Linguísticos) Instituto de Biociências, Letras e Ciências Exatas, Universidade Estadual Paulista, São José do Rio Preto, 2009.

17. SCHOFFEN, Juliana Roquele; MARTINS, Alexandre Ferreira. Políticas linguísticas e definição de parâmetros para o ensino de português como língua adicional: perspectivas portuguesa e brasileira. ReVEL: revista virtual de estudos da linguagem, [S. I.], v. 14, n. 26, 2016.

18. SILVA, Grazielle Roberta Freitas; MACÊDO, Kátia Nêyla de Freitas; REBOUÇAS, Cristiana Brasil de Almeida; SOUZA Ângela Maria Alves. Interview as a technique of qualitative research: a literature review. Online Brazilian Journal of Nursing, Niterói, v. 5, n. 2, 2006. Disponível em: https://www.objnursing.uff.br/index.php/nursing/article/view/382/88. Acesso em: 15 mar. 2019.

19. SILVESTRE, Viviane Pires Viana; BROSSI, Giuliana. Castro; BORELLI, Julma Dalva Vilarinho Pereira. Uma proposta crítica de oficinas temáticas de inglês em uma escola pública: ações docentes e reflexões discentes. REVELLI: revista de educação, língua e literatura, Inhumas, v. 9, p. 48-66, 2017.

20. TANACA, Jozélia Jane Corrente. Aprendizagem expansiva em espaços híbridos de formação continuada de professoras de inglês para crianças no Projeto Londrina Global. 2017. 257 f. Tese (Doutorado em Estudos da Linguagem) - Universidade Estadual de Londrina, Londrina, 2017.

21. TONELLI, Juliana Reichert Assunção. Contextos (in)explorados no estágio supervisionado nas licenciaturas em Letras/Inglês: o lugar da observação de aulas nos dizeres de alunos-mestres. Signum: estudos da linguagem, Londrina, v. 19, n. 2, p. 35-65, 2016.

22. TONELLI, Juliana Reichert Assunção. Professores de línguas adicionais para crianças: atores de espaços vazios? In: REIS, Simone (org.). História, políticas e ética na área profissional da linguagem. Londrina: EDUEL, 2017. p. 67-84. 
23. TONELLI, Juliana Reichert Assunção; CRISTOVÃO, Vera Lúcia Lopes. O papel dos cursos de Letras na formação de professores de inglês para crianças. Revista Calidoscópio, São Leopoldo, v. 8, n. 1, p. 65-76, jan./abr. 2010.

24. TONELLI, Juliana Reichert Assunção; FERREIRA, Otto Henrique; BELO-CORDEIRO, Aretha Estefane. Remendo novo em vestido velho: uma reflexão sobre os cursos de Letras-Inglês. REVELLI: revista de educação, língua e literatura, Inhumas, v. 9, p. 124-141, 2017.

25. UNIVERSIDADE ESTADUAL DE GOIÁS - UEG. Projeto pedagógico do curso de licenciatura em letras. Inhumas: UEG, 2018.

26. UNIVERSIDADE ESTADUAL DE LONDRINA - UEL. Resolução CEPE/CA n . 119/2018. Reformula o Projeto Pedagógico do Curso de Letras Inglês - Licenciatura em Língua Inglesa e Literaturas em Língua Inglesa, a ser implantado a partir do ano letivo de 2019. Londrina: UEL, 2018.

27. VERTOVEC, Steven. Super-diversity and its implications. Ethnic and Racial Studies, Londres, v. 2, n. 6, p. 1024-1054, 2007.

28. YIN, Robert. Estudo de caso: planejamento e métodos. 3. ed. Porto Alegre: Bookman, 2005.

\section{Giuliana Castro Brossi}

Docente no curso de Letras da Universidade Estadual de Goiás/ Campus Inhumas - Doutoranda no Programa de Pós-graduação em Estudos da Linguagem na Universidade Estadual de Londrina

\section{Mariana Furio}

Docente no Departamento de Letras Estrangeiras Modernas da Universidade Estadual de Londrina. Doutoranda no Programa de Pós-graduação em Estudos da Linguagem na Universidade Estadual de Londrina

\section{Juliana Reichert Assunção Tonelli}

Professora Adjunta no Departamento de Letras Estrangeiras Modernas da Universidade Estadual de Londrina. Doutora em Estudos da Linguagem e Pós doutora em Linguística Aplicada.

\section{Como citar este documento:}

BROSSI, Giuliana Castro; FURIO, Mariana; TONELLI, Juliana Reichert Assunção. Currículo e formação de professores de Inglês em duas universidades: questões e desdobramentos. Reflexão e 
Ação, Santa Cruz do Sul, v. 28, n. 3, p. 96-112, ago. 2020. ISSN 1982-9949. Disponível em: $<$ https://online.unisc.br/seer/index.php/reflex/article/view/14310>.

Acesso em: doi:https://doi.org/10.17058/rea.v28i3.14310. 